\title{
Professional Ethics; an Approach to Value Creation in Financial Reporting
}

\author{
Bahram Meihami ${ }^{1}$, Zeinab Varmaghani ${ }^{2}$, Hussein Meihami ${ }^{3}$, \\ Mohammad Khaledian ${ }^{4}$ \\ ${ }^{1}$ Department of Accounting, Ghorveh Branch, Islamic Azad University, Ghorveh, Iran \\ ${ }^{2}$ BA Student of Primary Education, Ghorveh Branch, Islamic Azad University, Ghorveh, Iran \\ ${ }^{3}$ Department of English Teaching, Ghorveh Branch, Islamic Azad University, Ghorveh, Iran \\ ${ }^{4}$ Department of Ghorveh Branch, Faculty of Psychology, Islamic Azad University, Ghorveh, Iran
}

\section{Removed article}


